\title{
EDITORIAL: SMST 2013
}

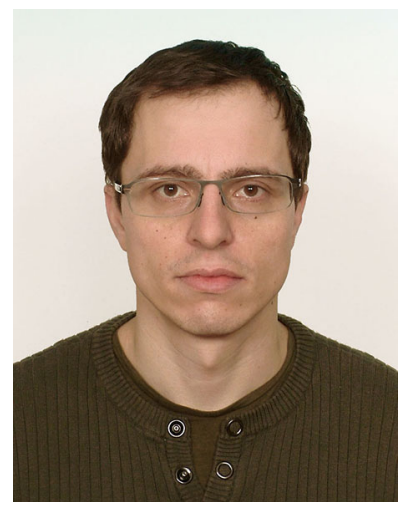

Luděk Heller

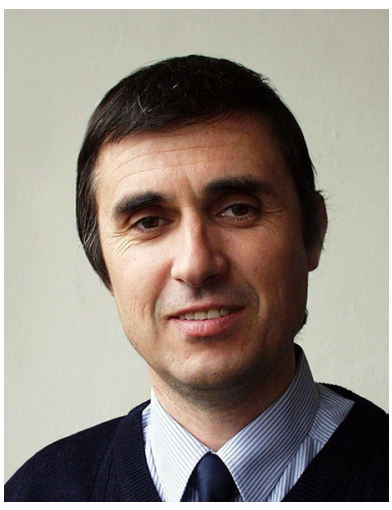

Petr Šittner

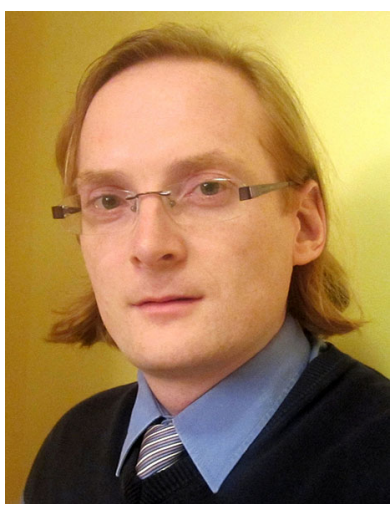

Petr Sedlák

The International Conference on Shape Memory and Superelastic Technologies - SMST 2013 - was held on May 21-24, 2013 in hotel Pyramida in Prague, Czech Republic. After SMST 2004 in Baden Baden, Germany and SMST 2008 in Stresa, Italy, it was for the third time that Europe hosted this top event of the shape memory and superelastic technologies community. The conference was sponsored by SMST, the International Organization on Shape Memory and Superelastic Technologies, an affiliate society of ASM International and locally endorsed by the Institute of Physics of the Academy of Sciences of the Czech Republic.

The SMST conferences are dedicated to latest technical and scientific developments in the area of shape memory and superelastic alloys and their applications to engineering problems. Particularly, it is the applications of superelastic NiTi alloys in medical devices, which united this community, and which continues to be the most commercially significant application area for NiTi alloys. The SMST 2013 in Prague continued this 20-year-old tradition and provided a get together forum for scientists, engineers, and academics working in this exciting research area merging with engineers and entrepreneurs from medical device industry. Besides the traditional SMST topics, new trends were pursued in Prague consisting in inviting researchers involved in designing and developing high temperature SMA actuators for aerospace, energy and transportation (a move firstly initiated SMST 2010), shape memory polymers, metal-polymer composites, and numerical modeling of SMAs and SMA structures.

SMST 2013 hosted 296 attendees from all over the world with the largest participation from Germany and USA. The conference program featured 223 presentations, including 8 plenary lectures, 117 oral talks, and 98 posters. The traditional pre-conference half day Nitinol Course organized by A. Pelton on Monday, May 20th, 2013 offered Nitinol technology related lectures given by leading specialists from US and Europe. This popular educational workshop attracted particularly young European researchers from medical device companies and university students who crowded the hundred seat lecture room. The Product Exhibition and Posters Sessions were organized on Tuesday and Thursday afternoons as a kind of exhibitor and poster receptions providing enough time for scientific discussions over new products, results and community affairs. After years, the SMST 2013 participants will probably remember the Wednesday's conference banquet in the stylish Club Lávka \& Bar restaurant located at the foot of the famous gothic Charles Bridge across the Vltava river offering exciting night views of the Prague Castle from its backyard. We gratefully acknowledge the work of the members of ASM International team, local organizers, SMST advisory committees, referees, session chairs, and particularly the sponsors, who stood behind the success of the third "SMST Europe" in Prague.

Special thanks to

Petr Šittner, SMST 2013 Chairman, Institute of Physics of the ASCR, Prague, Czech Republic

Matthias Mertmann, SMST President, Memry GmbH, GMBh, Weil Am Rhein, Germany

Ausonio Tuissi, SMST 2013 Co-chair, CNR IENI, Lecco, Italy

Jan Van Humbeeck, SMST 2013 Co-chair, Departement MTM, KU Leuven, Leuven, Belgium

Denis Favier, Université Grenoble, Grenoble, France

Martin F.-X. Wagner, SMST 2013 Co-chair, Chemnitz University of Technology, Chemnitz, Germany

Dieter Stoeckel, SMST 2013 Co-chair, NDC, Fremont, CA, USA 
Among the 12 sessions that formed the four day technical program of SMST 2013, there were six general sessions and six special focused sessions organized by leading specialists around the topics of their particular interests.

- Advanced SMA Forms and Functions

- Aerospace, Automotive, Space, and Civil Engineering Applications

- Application-Driven Methods of SMAs Testing

- Functional Properties of Shape Memory Materials

- How to Test NiTi Medical Devices

- New Methods, Experiments, and Future Directions

- Production, Processing, and Joining

- SMA Microdevices and Microactuators

- SMA Modeling for Biomedical Devices

- Shape Memory Materials in Medicine

- Shape Memory Polymers and Hybrids

- Surface Engineering, Corrosion, and Biological Response

For the first time, the SMST 2013 conference proceedings were prepared in a form of digital collection of short articles with conference program (215 extended two page abstracts) available in PDF form for conference attendees already during the event. After the conference, this digital collection gives a very nice, quick, and complete overview on the work presented at the conference. We are happy to see that this tradition, which in fact started with printed collection of extended abstracts from SMST 2010, has continued in a slightly modified way at SMST 2014 so that, together with the SMST 2013 conference proceedings, a complete set of graphical abstracts from SMST 2014 can already be downloaded from the conference proceedings website of ASM International, http://www.asminternational.org/conferences/resources/conference-proceedings.

For those who want to get even more complete information, this special issue of the Journal of Materials Engineering and Performance brings a collection of more than 60 selected articles based on the work presented at SMST 2013. We thank all authors who accepted our invitation to submit their manuscripts for publication of their full length peer-reviewed articles in JMEP. We thank Diane Whitelaw, JMEP's Production Coordinator, for facilitating the manuscript review, monitoring, and controlling manuscript flow, and ensuring timely publication of the special issue. To ease the orientation of the readers, the special issue is organized along the 12 session topics listed above. Please enjoy reading and consider attending SMST 2015 in Heythrop Park Resort, Oxfordshire, UK, http://www.asminternational.org/web/smst-2015-event/home.

\section{Luděk Heller \\ Institute of Physics of the ASCR \\ Prague, Czech Republic}

\section{Petr Šittner}

Institute of Physics of the ASCR

Prague, Czech Republic

\section{Petr Sedlák}

Institute of Thermomechanics of the ASCR

Prague, Czech Republic 